\title{
Perspective
}

PERSPECTIVE Actualité en histoire de l'art

1 | 2012

Art et pouvoir

\section{Le pouvoir des images : des médias visuels aux médias sociaux}

The power of images: from visual media to social media

\section{Peter Weibel}

Traducteur : Pierre Rusch

\section{OpenEdition \\ Journals}

Édition électronique

URL : http://journals.openedition.org/perspective/406

DOI : $10.4000 /$ perspective.406

ISSN : 2269-7721

\section{Éditeur}

Institut national d'histoire de l'art

Édition imprimée

Date de publication : 30 juin 2012

Pagination : 5-7

ISSN : 1777-7852

Référence électronique

Peter Weibel, « Le pouvoir des images : des médias visuels aux médias sociaux », Perspective [En

ligne], 1 | 2012, mis en ligne le 14 août 2013, consulté le 10 décembre 2020. URL : http://

journals.openedition.org/perspective/406; DOI : https://doi.org/10.4000/perspective.406 


\section{Le pouvoir des images : des médias visuels aux médias sociaux}

De la Bible au Prince de Machiavel, les lettres et les livres ont constitué le vecteur privilégié du pouvoir - le fondement mystique de la force de loi, pour paraphraser un titre de Jacques Derrida ${ }^{1}$. L'empereur Gaius Julius Caesar Octavianus, connu sous le nom d'Auguste, aurait le premier découvert le pouvoir des images, déployant une stratégie inédite afin d'assurer sa domination absolue. En élevant de nombreux édifices et en multipliant ses portraits en tous lieux et sur tous supports, il est parvenu à imposer une image de sa personne et de son autorité qui, bien que fictive, a posé les bases du mythe de la pax romana ${ }^{2}$.

Avec la multiplication des images, grâce aux progrès techniques et de reproduction au début de la Période moderne, l'écrit a perdu le monopole du pouvoir. Les puissances terrestres, comme les puissances célestes, réclamaient des images à leur gloire, et les intérieurs des églises et des palais s'ornèrent de peintures toujours plus élaborées, toujours plus somptueuses. Cependant la peinture, créée à la demande de commanditaires ecclésiastiques et princiers, fut rapidement soupçonnée de servir les puissants. À partir de l'analyse du pouvoir de Michel Foucault, on peut déduire que toute image faite en ces circonstances a pour tâche de représenter, et donc de conforter, le pouvoir en place. Plus récemment, l'historien de l'art Wolfgang Ullrich a montré combien, dans les démocraties actuelles, que le régime soit présidentiel ou parlementaire, les images et les bâtiments servent, comme au temps d'Auguste, à manifester la puissance des gouvernants ${ }^{3}$.

$\mathrm{Au}$ pouvoir des textes s'ajouta donc le pouvoir des images, qui déstabilisa le monopole des lettres sans toutefois le supprimer. La conséquence en fut la démultiplication du pouvoir de représentation. Mais dès le milieu du XVI siècle, des protestations s'élevèrent contre ce pouvoir affiché dans la sphère publique, à l'instar des iconoclasmes protestants. Plus proche de nous, l'art du XX $X^{e}$ siècle, depuis Marcel Duchamp, fut également traversé par de puissantes pulsions iconoclastes. Tout art critique, surtout s'il vise le pouvoir, est par nature "contre la représentation ${ }^{4}$.

Le pouvoir des images s'est accru depuis le milieu du XIX $X^{e}$ siècle avec l'apparition de la photographie, puis des médias visuels que sont le cinéma, la télévision, la vidéo et l'ordinateur. Nous sommes entrés dans " l'univers des images techniques " ${ }^{5}$, et la peinture a perdu le monopole de la fabrication des images que les artistes avaient défendu jusque-là ${ }^{6}$. Alors que la production et le pouvoir des images se sont amplifiés avec l'essor des nouveaux médias, l'image peinte, restée attachée à un lieu particulier et soumise à la logique de la production, a perdu de son efficace. Les images des nouveaux médias, quant à elles, suivent la logique de la distribution, pouvant être reproduites, diffusées, et réceptionnées presque simultanément par une foule de destinataires. L'œuvre d'art insiste sur son unicité ; les images techniques se fabriquent en série. La première n'atteint le grand public qu'après avoir été transformée en images médiatiques, intégrée sous forme de photographies dans un livre ou diffusée à la télévision. Pour la plupart, les images publiques ne relèvent plus du monde de l'art ni de la création individuelle, mais font partie intégrante des médias de masse. Presque toujours tirées des journaux, des revues, des affiches, des panneaux publicitaires, du cinéma ou de la télévision, elles sont produites industriellement par des entités collectives telles que des 
firmes et des agences. Ainsi, l'espace public se trouve presque entièrement occupé ou colonisé par des images du pouvoir, qu'il soit commercial ou politique. Dans cette optique, les nouveaux iconoclastes sont les graffiteurs anonymes qui conçoivent des interventions subjectives dans l'espace public que peuplent les images du pouvoir. Ce faisant, ils critiquent le pouvoir de la représentation et, plus exactement, le pouvoir de l'image.

Vers 1950, soit cent ans après la découverte de la photographie et l'entrée triomphale des images techniques dans les médias de masse, on s'est aperçu que la culture visuelle comprenait bien davantage que les seuls arts visuels. Si la controverse académique entre les visual arts et la visual culture n'a vraiment démarré que dans les années 1980, les bases en ont été posées dès 1950. Dans The Mechanical Bride: Folklore of Industrial Man paru en 1951, Marshall McLuhan a étudié, à partir d'un échantillon de textes et d'images, les effets de la publicité sur la société et la culture. Le chercheur analyse non pas des images artistiques, mais des images commerciales, car la culture visuelle des médias de masse lui a semblé plus intéressante que les images tirées de l'histoire de l'art pour diagnostiquer son époque et établir un constat sur l'état de la société. De la même manière, en 1950, le philosophe Martin Heidegger a résumé la transformation du monde sous la pression des médias visuels de masse en ces termes : " Le processus fondamental des Temps modernes, c'est la conquête du monde en tant qu'image. Le mot image signifie maintenant la configuration (Gebilde) de la production représentante " ${ }^{7}$. Par "production représentante", Heidegger décrit le fait que la représentation devient elle-même un acte d'instauration ontologique. Heidegger, le philosophe de l'Être, annonce ici Jean Baudrillard, le philosophe de la simulation, et sa thèse de la "précession des simulacres ${ }^{8}$ : la représentation vient avant la production ; l'image vient avant la " configuration », la simulation avant l'Être. Le pouvoir de l'image n'est pas seulement omniprésent dans la culture visuelle, il est aussi tout-puissant. Des images de l'histoire de l'art à celles des médias visuels de masse, des arts visuels à la culture visuelle, l'image poursuit sa marche triomphale.

Avec l'apparition d'Internet, couronnement de la logique de la distribution, les médias de masse et leurs propriétaires ont toutefois perdu le monopole de l'image. Les artistes ont d'abord été évincés par les producteurs et les diffuseurs d'images techniques ; c'est maintenant au tour de ces derniers de perdre le monopole de la production et de la distribution des images au profit des usagers des réseaux sociaux. C'est pourquoi nous ne parlons pas aujourd'hui de médias visuels, mais de médias sociaux, par lesquels les utilisateurs participent pleinement au processus de diffusion. Les usagers ne sont plus seulement les "destinataires " mais aussi les "destinateurs", les auteurs des messages, prenant en charge "la configuration de la production représentante ". Ils produisent eux-mêmes la représentation et participent de ce fait du pouvoir de la représentation. Si, dans la culture visuelle des médias de masse, "le médium [est] le message " (Marshall McLuhan), dans les médias sociaux " chacun est destinateur" (Peter Weibel).

Cette évolution constitue le dernier assaut de l'avant-garde contre la représentation. Car l'événement majeur dans l'art du XXe siècle n'est pas l'abstraction, c'est-à-dire l'autoreprésentation des moyens de représentation (point, ligne, surface, couleur, etc.) ; c'est l'autoreprésentation de la réalité. La critique de la représentation culmine dans la substitution de la réalité à la représentation. Tout ce qui a été peint jusque-là se trouve désormais remplacé par des choses et des êtres réels : les tableaux de paysage par le Land Art, les portraits par le Body Art, la lumière naturelle (représentée au moyen de la couleur) par une vraie lumière artificielle, les peintures d'intérieur par des " environnements " réels, les peintures historiques par des événements réels, par des actions et des interactions avec un public réel. $\mathrm{C}^{\prime}$ est l'autoreprésentation de la réalité, la réalité elle-même qui se donne à voir ${ }^{9}$. Les médias visuels étaient l'expression de la fonction classique de l'art, c'est-à-dire de la représentation ; 
substituer les médias sociaux aux médias visuels conduit à mettre l'action à la place de la représentation, la participation à la place de la réception, l'utilisation à la place de la contemplation ${ }^{10}$. Communiquer sur Internet, envoyer des textes et des images, c'est agir, c'est participer à la production et à la diffusion des images. Réparti entre les usagers, le pouvoir de l'image se trouve distribué, et ainsi s'amenuise. L'image et le pouvoir, l'art et le pouvoir entrent dans une nouvelle relation. Les médias sociaux brisent la puissance des images des médias visuels. Le pouvoir performatif est atomisé ; tous apprennent à créer avec des images et des mots ${ }^{11}$. Le pouvoir des lettres et le pouvoir des images s'éparpillent et se dissolvent dans les médias sociaux, où tout un chacun peut agir, au lieu d'être seulement représenté.

Ce texte a été traduit par Pierre Rusch.

1. Jacques Derrida, Force de loi : le "fondement mystique de l'autorité ", Paris, 1994.

2. Paul Zanker, Augustus und die Macht der Bilder, Munich, 2008.

3. Wolfgang Ullrich, Tiefer hängen: Über den Umgang mit der Kunst, Berlin, 2003, ainsi que Macht zeigen: Kunst als Herrschaftsstrategie, Wolfgang Ullrich éd., (cat. expo., Berlin, Deutsches Historisches Museum, 2010), Berlin, 2010.

4. "Plus jamais de représentation ", déclarait Alexander Rodchenko en 1921, à l'époque où il réalisait les trois premières toiles monochromes de l'histoire de l'art (cité dans Von der Malerei zum Design - Russische konstruktivistische Kunst der zwanziger Jahre, [cat. expo., Cologne, Galerie Gmurzynska, 1981], Cologne, 1981, p. 191).

5. Vilém Flusser, Ins Universum der technischen Bilder, Göttingen, 1999.

6. Aussi tard que 1937, l'un des plus éminents photographes du XX⿳亠丷厂 siècle, Man Ray, publia un recueil de ses clichés sous le titre La Photographie n'est pas l'art (Paris, 1937).

7. Martin Heidegger, Chemins qui ne mènent nulle part, Paris, 1962, p. 123 (traduction adaptée) [éd. orig. : Holzwege, Francfort, 1950].

8. Jean Baudrillard, "La précession des simulacres ", dans Traverses, 10, Paris, 1978.

9. Samson Dietrich Sauerbier, Gegendarstellung. Ästhetische Handlungen und Demonstrationen: Die zur Schau gestellte Wirklichkeit in den zeitgenössischen Künsten, Cologne, 1976.

10. Franz Erhard Walther, Objekte, benutzen, Cologne, 1968.

11. John Langshaw Austin, Quand dire c'est faire, Paris, 1970 [éd. orig. : How to Do Things with Words, Cambridge, 1962]. Sur la question du rôle du spectateur, voir également Jacques Rancière, Le Spectateur émancipé, Paris, 2008. 